\title{
Escolas saudáveis: o papel do território educativo no contexto da pandemia de COVID-19
}

\author{
Mariana Campos Demuth ${ }^{1}$ \\ Ana Beatriz Goulart de Faria ${ }^{2}$ \\ Anna Ayumy Inoue Pompeia ${ }^{3}$ \\ Carolina Mesquita Clasen ${ }^{4}$ \\ Debora Laub ${ }^{5}$ \\ Gabriela Gerotto Viola ${ }^{6}$ \\ Heloisa Bento Ribeiro ${ }^{7}$
}

\begin{abstract}
Resumo:
A presente reflexão foi produzida a partir da experiência de elaboração do Manual Técnico para Escolas Saudáveis, desenvolvido em agosto de 2020 pelo GT Cidade, Infâncias e Juventudes do IAB-SP que, ao descrever as medidas necessárias para um ambiente escolar saudável em um momento de pandemia, coloca em evidência problemas estruturais mais amplos das escolas públicas da rede estadual de São Paulo. Na investigação acerca do que torna uma escola saudável, surge ainda uma pergunta anterior: o que é, afinal, um espaço saudável? O que está por trás desta concepção? A partir disso, revisitando questões que emergem da construção coletiva de um espaço de educação saudável em sua totalidade - incluindo edifício, território, currículo e gestão -, é proposto um levantamento dos fatores que, para além da arquitetura, envolvem a saúde não apenas dos espaços escolares, mas também das experiências corpóreas entre escola, sua comunidade e o território do qual faz parte.
\end{abstract}

\section{Palavras-chave:}

Escolas saudáveis. Território educativo. Gestão democrática. Arquitetura escolar. COVID-19.

1 Formada em Arquitetura e Urbanismo e mestre em Design pela USP. Estudante de pós-graduação em Arte Educação no SENAC e faz parte do GT Cidade, Infâncias e Juventudes. E-mail: mariana.demuth@gmail.com ORCID iD: http://orcid.org/00000002-3704-0327

2 Arquiteta-urbanista, membro do Centro de Referências em Educação Integral e professora na Fábrica-escola de humanidades, faz parte do GT Cidade, Infâncias e Juventudes do IAB-SP. E-mail: byagoulart@gmail.com ORCID iD: http://orcid.org/00000003-2346-4820

3 Arquiteta e urbanista, integrante do Coletivo de Extensão Universitária CoCriança, da FAU-USP, e faz parte do GT Cidade, Infâncias e Juventudes do IAB-SP. E-mail: anna.pompeia@usp.br ORCID iD: http://orcid.org/0000-0002-5476-1572

4 Arte-educadora, Mestre em Arquitetura e Urbanismo PROGRAU-UFPel (2018). Faz parte do GT Cidade, Infâncias e Juventudes do IAB-SP. E-mail: carolina.mescla@gmail.com ORCID iD: http://orcid.org/0000-0003-3859-4791

5 Arquiteta e Urbanista, finalizará o doutorado em março de 2022. Faz parte do GT Cidade, Infâncias e Juventudes do IAB-SP. E-mail: deboralaub@usp.br ORCID iD: http://orcid.org/0000-0001-6835-1614

6 Arquiteta e Urbanista, faz parte do CoCriança, um Projeto de Extensão e Cultura da FAU-USP e do GT Cidade, Infâncias e Juventudes do IAB-SP. E-mail: gabrielagviola@gmail.com ORCID iD: http://orcid.org/0000-0001-7474-1272

7 Arquiteta e Urbanista, cursa a pós-graduação “Arquitetura, Educação e Sociedade" na Escola da Cidade, onde também é Professora Assistente da disciplina de Urbanismo. Faz parte do GT Cidade, Infâncias e Juventudes do IAB-SP. E-mail: heloisabribeiro@gmail.com ORCID iD: http://orcid.org/0000-0002-9849-0209 


\title{
Healthy schools: the role of educational territory in the context of the Covid-19 pandemic
}

\begin{abstract}
:
The present paper was produced from the experience of drafting the Technical Manual for Healthy Schools, developed in August 2020 by the working group called City, Children and Youth of the Institute of Brazilian Architects - São Paulo. This manual describes the measures needed for a healthy school environment in a moment of Covid-19 pandemic and highlights the structural problems of public schools in the state of São Paulo. In researching what makes a school healthy, an earlier question arises: what is, after all, a healthy space? What is behind this conception? From that, revisiting issues that emerge from the collective construction of a healthy educational space in its entirety - including building, territory, curriculum and management - it is proposed a survey of the factors that, beyond architecture, involve the health not only of school spaces, but also of the corporeal experiences between school, its community and the territory of which it is part.
\end{abstract}

Keywords:

Healthy schools. Educational territory. Democratic management. School architecture. Covid-19.

\section{Escuelas saludables: el papel del territorio educativo en el contexto de la pandemia Covid-19}

\section{Resumen:}

La presente reflexión se produjo a partir de la experiencia de elaboración del Manual Técnico para Escuelas Saludables, desarrollado en agosto de 2020 por el GT Ciudad, Infancias y Juventuds del IAB-SP (Instituto de Arquitectos de Brasil), que, al describir las medidas necesarias para un ambiente escolar saludable en un momento de pandemia, pone de relieve problemas estructurales más amplios de las escuelas públicas en el estado de São Paulo. En la investigación sobre qué hace que una escuela sea saludable, surge una pregunta previa: ¿qué es, en definitiva, un espacio saludable? ¿Qué hay detrás de esta concepción? A partir de ello, revisando las cuestiones que surgen de la construcción colectiva de un espacio educativo saludable en su totalidad - incluyendo el edificio, el territorio, el currículo y la gestión - se propone un levantamiento de los factores que, más allá de la arquitectura, involucran la salud no sólo de los espacios escolares, sino también de las experiencias corporales entre la escuela, su comunidad y el territorio del que forma parte.

Palabras clave:

Escuelas saludables. Territorio educativo. Gestión democrática. Arquitectura escolar. Covid-19.

\section{Introdução}

O ano de 2020 apresentou um dos momentos mais desafiadores e complexos dos últimos tempos. A pandemia de COVID-19 trouxe adversidades que englobam toda a população brasileira, escancarando um quadro de desigualdade historicamente estabelecido e acentuado frente à crise. A garantia de direitos básicos como saúde, moradia e educação passa a demandar uma agilidade de respostas estratégicas para problemas que se atualizam a cada dia. A qualidade da infraestrutura dos ambientes - de trabalho, estudo, moradia ou lazer - foi acirrada no que se refere a sua salubridade. Deste quadro, emerge um tema estrutural que, sendo urgente à saúde e ao desenvolvimento adequado de crianças e jovens, estende-se a suas famílias, sendo fundamental para toda a sociedade: 
o que torna os espaços da escola saudáveis? Foi buscando abrir diálogos e construir caminhos em torno desta questão que foi produzido o Manual Técnico para Escolas Saudáveis ${ }^{8}$, documento que reúne recomendações morfológicas para escolas públicas, no contexto do Estado de São Paulo.

O processo de constituição do manual foi pautado na pesquisa qualitativa, partindo do referencial teórico apresentado pelos protocolos sanitários e da coleta de dados acerca das condições das escolas no Estado de São Paulo, a serem apresentados nos parágrafos que seguem. Tendo em vista que esse campo de estudo abrange mais de 5 mil escolas, optou-se por utilizar como recorte temático as escolas cujo projeto arquitetônico se enquadra no padrão da Fundação para o Desenvolvimento da Educação $(\mathrm{FDE})^{9}$ - órgão estadual responsável pelas edificações escolares do Estado de São Paulo, desde 1987. Assim, com o objetivo de estabelecer diretrizes para espaços mais saudáveis, o projeto escolar padrão da FDE foi analisado em três âmbitos: os espaços internos da escola, os espaços externos da escola e os espaços do entorno. O presente artigo apresenta esse processo metodológico, as conclusões e as reflexões que dele emergiram.

\section{O Manual Técnico para Escolas Saudáveis}

Para elaboração do referido manual, em primeiro lugar, foram considerados documentos realizados para diferentes contextos, publicados com o intuito de trazer respostas estratégicas aos entraves colocados pela pandemia, sendo eles: Reopening America: Strategies for safer schools (2020); Marco de ação e recomendações para a reabertura de escolas (2020); Procedimentos de reabertura institucional na pandemia da COVID-19 (2020); Documento com Sugestões sobre o planejamento de reabertura das escolas e aprendizagem ao ar livre (2020); Protocolos sobre educação inclusiva durante a pandemia da COVID-19: um sobrevoo por 23 países e organismos internacionais (2020). A partir da análise destes documentos, foi possível determinar diretrizes gerais que podem ser consideradas para qualquer espaço educativo. No entanto, apesar dessas diretrizes serem fundamentais para um entendimento amplo, um dos objetivos do manual foi contextualizar essas medidas para as especificidades encontradas no Estado de São Paulo - de quesitos climáticos e demográficos às condições físicas dos edifícios - buscando, assim, alcançar maior proximidade a possíveis ações por parte da comunidade escolar, além de um monitoramento fiel dos dados, sempre respaldado na orientação de profissionais da saúde e da comunidade científica nacional e internacional.

O manual revisou dados publicados pela Secretaria de Educação do Estado de São Paulo, do Inep (2019) e do IBGE (2020), em recorte que compreende as escolas estaduais de ensino fundamental e médio. Neste contorno, aborda-se uma comunidade bastante diversa de mais de 3,8 milhões de estudantes, 200 mil professores e 40 mil funcionários, distribuídos em cerca de 5.200 edifícios escolares $^{10}$. São escolas localizadas no cerrado ou na mata atlântica, em áreas rurais ou urbanas, em territórios com diferentes qualidades de infraestrutura (rede de esgoto, potabilidade da água, qualidade das moradias, presença de áreas verdes, entre outros) e em territórios múltiplos, como quilombos, assentamentos, tribos indígenas, penitenciárias e hospitais. Escolas que, muitas

\footnotetext{
8 Disponível em: https://www.iabsp.org.br/iab_apeosep_manual_escolas_saudaveis.pdf. Acesso em: 04 maio 2021.

9 Disponível em: https://www.fde.sp.gov.br. Acesso em: 04 maio 2021. A FDE é responsável por viabilizar a execução das políticas educacionais definidas pela Secretaria da Educação do Estado de São Paulo, implantando e gerindo programas, projetos e ações destinadas a garantir o bom funcionamento, o crescimento e o aprimoramento da rede pública estadual de ensino. Entre suas principais atribuições estão construir escolas, reformar, adequar e manter os prédios, salas de aula e outras instalações; oferecer materiais e equipamentos necessários à educação; gerenciar os sistemas de avaliação de rendimento escolar; e viabilizar meios e estruturas para a capacitação de dirigentes, professores e outros agentes educacionais e administrativos, visando sempre à melhor qualidade do ensino e à aplicação apropriada das políticas educativas definidas pelo Estado.

10 Secretaria de Educação do Estado de São Paulo; IBGE, 2020.
} 
vezes, se encontram em condições precárias por falta de manutenção, não apresentando alguns dos recursos mais básicos.

A partir das recomendações e protocolos analisados, o manual tem por intuito agregar e sintetizar as orientações para ambientes escolares, aprofundando-se nestas particularidades do Estado de São Paulo. Sem reduzir-se apenas à questão pandêmica, na reflexão abrangente sobre o que torna ambientes saudáveis, faz-se necessário reconhecer e estabelecer nas escolas aspectos que contribuem, em todos os momentos, para evitar outros tipos de infecção. Deste complexo contexto, emerge a necessidade de uma abordagem interdisciplinar que, articulando saúde, arquitetura e educação, coloca em pauta o papel e a importância de um ambiente escolar confortável e acolhedor que, além de ser em si elemento pedagógico, revela-se também com um equipamento fundamental de apoio à saúde pública.

Em função dos protocolos de distanciamento social, os meses de reclusão evidenciaram ainda mais a escola como importante lugar de encontro. Se, anteriormente, sair das salas de aula apertadas era desejo de muitos alunos e professores, agora este desejo aparece como uma via necessária. Nesse contexto, é posto em pauta o modelo de escola vigente, dando margem para refletir e sonhar coletivamente um novo arranjo de educação.

\section{O problema: crise na educação}

Com base nos dados ${ }^{11}$ apresentados pelo Manual Técnico para Escolas Saudáveis, 99\% das escolas estaduais paulistas não têm enfermaria, consultório médico ou ambulatório; $11 \%$ não têm pátio e 13\% não têm quadra (2020, p. 17). Quanto aos sanitários, fundamentais para os protocolos de higienização e controle do espraiamento do vírus, $82 \%$ das escolas do Estado apresenta apenas dois sanitários para uso dos estudantes e $48 \%$ não conta com sanitário acessível. Já nas salas de aula, frequentemente superlotadas, faz-se necessária uma redução do número de indivíduos no espaço, de modo a garantir o distanciamento social recomendado. Estabelece-se que $93,4 \%$ das salas de aula de escolas estaduais de ensino fundamental e médio de São Paulo deveriam ser readequadas para a situação pandêmica vigente ${ }^{12}$.

Esse cenário de precarização, escancarado pela pandemia, culmina em uma crise que se estende desde a década de 1980 com o avanço do neoliberalismo (SANTOS, 2020, p. 13). O risco desse momento, no entanto, é apresentado por uma situação que é duplamente anômala, ou seja, uma situação capaz de: I) "oportunizar a superação e a inauguração de um melhor estado das coisas" ou, quando dada de maneira permanente; II) "transforma-se na causa que explica todo o resto" (SANTOS, 2020, p. 13). Para acompanhar as reflexões do sociólogo Boaventura Santos, é possível perceber a crise da educação - enfatizada pela COVID-19 - talvez como inauguração de outras possibilidades. Observa-se que a insuficiência dos encontros à distância frente à suspensão das atividades presenciais se apresenta como momento substancial para repensar as escolas de maneira ainda mais comunitária, em contraponto ao risco de uma nova prática regulatória e higienista.

A pandemia desnudou a pobreza, a desigualdade social e étnica/racial, a ausência da garantia de direitos e a fragilidade e precariedade das estruturas dos serviços públicos, incluindo a qualidade da educação escolar e sua infraestrutura física. Segundo a socióloga e pós-doutora em educação, Helena Singer, isto abalou a forma e a organização escolar, seus tempos e espaços, além de expor fraturas pré-pandêmicas.

11 Secretaria de Educação do Estado de São Paulo; IBGE, 2020

12 Respeitando o distanciamento de 1,5 metros estabelecido pela OMS e utilizando o tamanho de sala padrão da FDE (7,20x7,20), o infográfico desenvolvido pelo GT Cidade, Infâncias e Juventudes do IAB/SP em conjunto com o DIEESE estabelece o parâmetro de, no máximo, 20 alunos por sala de aula ao mesmo tempo. Disponível em: https://www.iabsp.org.br/infografico_covid19.pdf. Acesso em: 04 maio 2021 
O mundo que levou à pandemia é profundamente marcado pela desigualdade, pela degradação social ambiental e pelo autoritarismo de bases colonial, machista e racista. Como já sabemos desde Bourdieu, Illich, Foucault e outros pensadores, a escola disciplinar, com sua estrutura baseada nos anos letivos, salas de aula, conhecimento fragmentado e provas, tem sua parcela de responsabilidade pela manutenção deste estado de coisas. (SINGER, 2020).

Neste contexto, os tempos e espaços se organizam de forma massificada e naturalizada, "tendo como base a compartimentação estandardizada dos tempos (aulas de 50 minutos), dos espaços (sala de aula), do agrupamento dos alunos (turmas por idade) e dos saberes (disciplinas), aos quais correspondem formas determinadas de divisão do trabalho entre os professores" (CANÁRIO, 2006, p. 15). Segundo o educador português Rui Canário, essa situação não é nada propícia aos processos educativos libertadores, alertando para a necessidade de reinventarmos a organização escolar. E, para isso, a própria forma do espaço escolar deve também ser desnaturalizada e reestruturada na direção de um ambiente saudável.

Frente a isso, surge inevitavelmente a pergunta: como mudar estas estruturas? Segundo Singer,

Precisamos de uma estrutura que garanta a interação pessoal educador-estudante, o acompanhamento individualizado das aprendizagens e, ao mesmo tempo, a experiência coletiva da construção do bem comum, do diálogo, da convivência, do cuidado com o outro, da diversidade. Mais do que nunca precisamos de oportunidades de exploração corporal e de convívio com a natureza. Se os prédios e a velha estrutura chamada enturmação não servem para isso, utilizemos todos os recursos disponíveis, inclusive os tecnológicos que agora os professores conhecem melhor, para criar a estrutura dos tempos e espaços que torne isso possível. (SINGER, 2020).

Nesse sentido, fica evidente a necessidade de proporcionar espaços de discussão coletiva entre os membros da comunidade escolar (alunos, professores, funcionários e famílias) de forma a pensar, democraticamente, em novas possibilidades para ocupar e vivenciar a escola, respondendo às demandas evidenciadas pela pandemia.

\section{Conceitos fundamentais}

A fim de articular o cenário das escolas estaduais de São Paulo com questões emergentes no campo da educação, foi fundamental compreender quais seriam as premissas e reflexões enunciadas para além do manual. Neste sentido, o entendimento dos conceitos de gestão democrática, educação integral e território educativo, aliados a questionamentos em relação às políticas curriculares vigentes no sistema educacional paulista, foram trazidos como forma de fundamentar tais reflexões. A análise trazida para esta escrita, se deu nas práticas de gestão do espaço escolar e seus modos, articuladas ao manual como ferramenta potente para apoiar debates entre os membros do grupo escolar na reabertura dos seus espaços.

A suspensão das rotinas e a impossibilidade de retomar as atividades em sala de aula por tempo indeterminado, somadas ao esforço gerado pelas modalidades à distância, destacaram a relevância do encontro, da criação sensível e das práticas coletivas como ferramentas pedagógicas. As tecnologias do currículo e as práticas educativas são mediadas pela organização da escola, e é a relação entre elas que constitui a dimensão do vivido no cotidiano escolar. Por isso, é preciso considerar as diversas experiências da comunidade escolar como arcabouço, cabendo aos seus participantes atribuir sentido aos processos desenvolvidos de maneira colaborativa.

Nesse contexto, a gestão democrática pode ser qualificada como "a forma dialogal, participativa com que a comunidade educacional se capacita para levar a termo um projeto pedagógico de 
qualidade e do qual nascem cidadãos ativos, participantes da sociedade" (CURY, 2007, p. 489), nos colocando diante da produção e o cuidado de si. Para garantir a gestão democrática, é indispensável que os debates referentes ao currículo e à educação acolham a realização ético-estética da escola, "permitindo serem ouvidas vozes nem sempre consideradas legítimas no discurso pedagógico" (IUNES; LEITE, 2010, p. 9), como as da própria experiência dos estudantes. Ou ainda, uma gestão capaz de proporcionar que, entre metas e debates, sejam identificados percursos e intensidades produzidos pelos encontros, pelos afetos e pela participação ativa.

Nesse sentido, fica evidente a importância da reflexão não apenas sobre os territórios que nos foram retirados desde a imposição das medidas de distanciamento, mas também, e principalmente, sobre a retomada da experiência da vida cotidiana, amputada nos marcos da modernidade, e que tem a possibilidade de amarrar a gestão democrática com as necessidades curriculares, a partir de uma proposta de educação integral.

A educação aqui é tomada em seu sentido mais amplo, o do desenvolvimento humano integral, da aprendizagem ao longo da vida individual e coletiva, de um conhecimento que traz em si a sustentabilidade como base da convivência entre as pessoas e o seu território. Compreende-se, assim, que a Educação Integral não se limita à educação escolar e está associada à formação plena, unindo educação formal, não formal e informal. Nesse sentido, a educação não é só uma preocupação do sistema escolar e da escola, mas um instrumento social e cultural imprescindível para a coesão comunitária e pessoal. (ARRUDA, 2020, p. 68).

É a partir da união entre educação formal, não formal e informal que o conceito "integral" toma corpo, caminhando para uma educação em um sentido mais amplo, exigindo também uma espacialidade que vai para além dos muros da escola, trazendo para todos os atores sociais responsabilidade educativa, seja através da escola, dos equipamentos existentes no bairro e na cidade, ou das próprias relações sociais cotidianas. Além disso, construir um ambiente escolar em conjunto com seu entorno comunitário é uma via possível para a preparação de escolas que buscam garantir a "criação de um currículo que ofereça experiências democráticas aos jovens" (APPLE; BEANE, 2001, p. 20).

A prerrogativa de uma educação integral, que leva em consideração o desenvolvimento humano como um todo, torna imprescindível olhar para os territórios onde essas escolas se encontram. Esses espaços do bairro e da cidade que fazem parte do dia a dia escolar e que são vivenciados por professores, alunos, funcionários e famílias representam um território muito potente que precisa ser explorado dentro do conceito de território educativo.

O território não é apenas o resultado da superposição de um conjunto de sistemas naturais e um conjunto de sistemas de coisas criadas pelo homem. O território é o chão e mais a população, isto é, uma identidade, o fato e o sentimento de pertencer àquilo que nos pertence. $\mathrm{O}$ território é a base do trabalho, da residência, das trocas materiais e espirituais e da vida, sobre os quais ele influi. Quando se fala em território deve-se, pois, de logo, entender que se está falando em território usado, utilizado por uma dada população. Um faz o outro, à maneira da celebre frase de Churchill: primeiro fazemos nossas casas, depois elas nos fazem... A ideia de tribo, povo, nação e, depois, de Estado nacional decorre dessa relação tornada profunda. (SANTOS, 2000, p. 47).

Se, como explica Milton Santos, o território acarreta todas as trocas humanas (SANTOS, 2000), é possível afirmar que o território educativo é aquele onde essas trocas acontecem no âmbito da educação. Nem sempre um espaço específico que pertence a um território educativo tem como objetivo ou função principal a produção de conhecimentos. Entretanto, ao se relacionarem entre 
si criando uma rede, esses espaços ganham novo significado, possibilitando a troca de saberes, a reflexão sobre a identidade individual e social e a construção de novos conhecimentos.

No centro de suas propostas está a abertura da escola para a comunidade, estabelecendo com ela novos pactos educativos de corresponsabilização pela educação de suas crianças e jovens, num processo de territorialização da educação. [...] o conceito de Território Educativo remete a uma concepção abrangente de educação, em que o processo educativo confunde-se com um processo amplo e multiforme de socialização. (BRASIL, 2009, p. 18).

A integração da escola ao território, criando uma rede a partir das relações sociais e vínculos estabelecidos - com outros equipamentos, estabelecimentos e espaços públicos -, possibilita não só a articulação da comunidade escolar, mas a construção de uma gestão democrática e de um currículo direcionado para a educação integral do indivíduo, buscando, além dos saberes científicos, outras formas de ver e de habitar a terra. "Se as pessoas não tiverem vínculos profundos com sua memória ancestral, com as referências que dão sustentação a uma identidade, vão ficar loucas neste mundo maluco que compartilhamos" (KRENAK, 2019, p. 14).

O território não é fixo. Se depende das trocas humanas, necessariamente está em constante mutação, ressignificando palavras, ideias, ações, comportamentos, formas de compreender e se relacionar com o mundo. O território educativo tem o importante papel de evidenciar essas mudanças, permanentemente resgatando o que já se foi para que novas experiências possam ser criadas. Também tem a responsabilidade de dar voz ao presente, garantindo a autonomia da população e permitindo a construção de um currículo que tenha como base a educação integral através de uma gestão democrática.

\section{Percursos de uma escola saudável}

Frente à demanda de reorganização dos tempos e espaços escolares de modo a respeitar os protocolos sanitários atualmente redefinidos, emerge a possibilidade de uma discussão coletiva acerca da qualidade desses espaços, envolvendo estudantes, pais, professores e funcionários em um esforço conjunto de repensar a escola. Após tanto tempo distante, para qual ambiente se deseja voltar? O modelo de escolarização vigente associa de maneira absoluta o ato de aprender com a experiência de estar encerrado na sala de aula (SINGER, 2020). Como enfrentar as bases que regem esse modelo? E como contribuir para um processo de aprendizagem que incorpore as vivências dos estudantes e seja mais próximo das famílias em toda sua pluralidade? Ainda, como a arquitetura se relaciona com essa discussão? E o urbanismo?

As diferentes escalas que fazem parte da composição da experiência escolar devem, como já mencionado, aproximar escola, comunidade e território na agenda para a construção de novas práticas pedagógicas. Com um entendimento cada vez mais consolidado de que a educação é, além de integral, permanente (FREIRE, 2001, p. 11), percebemos que a construção de conhecimento se dá também na interação entre as pessoas e com os espaços, sendo as discussões sobre currículo e gestão nas escolas cada vez mais influenciadas pelas reflexões sobre territórios educativos.

Nesse contexto, as orientações de âmbito arquitetônico devem levar em conta não somente os protocolos sanitários e as normas técnicas que regem um edifício, mas também caminhar no sentido de um processo projetual capaz de configurar ambientes genuinamente saudáveis, ou seja, capazes de proporcionar bem-estar físico e mental. Para isso, é preciso uma abordagem interdisciplinar, que vá além da acessibilidade, do conforto térmico, bom desempenho acústico e luminotécnico, presença de áreas externas qualificadas e do contato com a natureza como aspectos fundamentais. O impacto do período de quarentena reverbera física e psicologicamente, trazendo 
luz à relevância do caráter coletivo dos espaços. Mais que um espaço de aprendizagem curricular, a escola é hoje valorizada enquanto lugar de convivência e de experiências relacionais. Sendo assim, de que formas o espaço, considerando todos os protocolos de segurança, pode contribuir para o encontro e a troca de forma democrática, proporcionando um desenvolvimento integral do ser?

\section{Permeabilidade, amplitude, colaboração e representação}

"Uma escola saudável precisa garantir espaços amplos para o movimento e a expressividade corporal" (INSTITUTO DOS ARQUITETOS DO BRASIL, 2020, p. 24). Reafirmar a troca de conhecimentos e experiências como fundamental para um ambiente escolar saudável, é retomar uma função do espaço que se realiza exatamente pela permeabilidade pensada no projeto arquitetônico. Ou seja, o projeto precisa ir além da pesquisa de materiais e elementos arquitetônicos, tendo como principal componente o questionamento sobre a morfologia dos espaços escolares e um programa de necessidades que considere uma gestão democrática, buscando o desenvolvimento integral dos indivíduos. Da mesma forma, a acessibilidade, fundamental em qualquer projeto, exige um olhar cuidadoso frente aos novos desafios e protocolos sanitários, que em geral pouco a consideram. A pandemia, dentre muitos outros males, atinge de maneira desproporcional as populações mais vulneráveis, que incluem pessoas com deficiência ou portadoras de necessidades especiais. Toda uma nova complexidade assola o ambiente escolar, enriquecendo a reflexão sobre como criar um espaço que, em contexto pandêmico ou não, seja adequado e possível para todos.

Ambientes amplos, em detrimento de ambientes pequenos e compartimentados, além de permitirem uma circulação confortável de pessoas, evitando aglomerações nos horários de entrada e saída dos estudantes, promovem a diversidade de usos, colaborando para uma pedagogia que valoriza a criatividade e a autonomia da comunidade escolar a partir da ocupação diversificada dos espaços.

Faz-se necessário pensar e conceber espaços efetivamente diversos e que permitam a autonomia de sua comunidade na reflexão sobre o modelo de gestão a ele atribuído. A diversidade e a autonomia são premissas de uma gestão democrática, que considera a pluralidade dos corpos como sujeitos corresponsáveis pela gestão escolar. Dessa forma, pensar em uma escola que se propõe a esse modelo de gestão, é pensar uma escola que tem a possibilidade de se reapresentar, acolhendo os diferentes corpos a partir de um novo cenário que preza pelo fortalecimento da coletividade, reforçando a necessidade de uma relação direta da escola com as famílias. Esse movimento fortalece o senso de responsabilidade e de cuidado com o bem comum, além de contribuir para a perenidade das ações realizadas.

\section{Urbanização para o pedestre e valorização dos espaços livres}

A partir do conceito de território educativo, fica evidente a importância de olhar para os espaços do bairro e da cidade, principalmente dentro do contexto pandêmico, onde é indicado o uso de espaços abertos e amplos. Conforme colocado, numa perspectiva de educação integral, o território é considerado elemento estratégico fundamental. A articulação de uma rede dialógica de apoio mútuo entre escola e outros agentes do território exige tanto um esforço interno do corpo escolar nos âmbitos da gestão e do currículo, quanto uma concepção de espaço público que permita e estimule essa formação de rede.

[...] que, por um lado, o conjunto do sistema educativo se envolva no tecido social da cidade e que o trabalho dos professores seja reconhecido; e por outro lado, é necessário que essa mesma 
sociedade assuma sua responsabilidade educativa, e que cada um dos agentes seja consciente de sua cota de responsabilidade. E, além disso, é importante também, que a cidade entenda e assuma que a educação é um elemento estratégico imprescindível para seu desenvolvimento harmônico e democrático. (GÓMEZ-GRANELL; VILA, 2003).

Para que o espaço da cidade seja uma extensão da sala de aula, os espaços públicos ao ar livre precisam ser devidamente adequados. Nesse sentido, é necessária a articulação de políticas intersetoriais (entre secretarias) e intrasetoriais (entre os sistemas públicos de educação) que favoreçam o diálogo constante entre as escolas e o poder público para um planejamento urbano que realmente atenda às necessidades de todos. A qualificação desses espaços se dá por meio de intervenções urbanas que priorizem o pedestre a partir de medidas que promovam segurança e conforto, como alargamento de calçadas, inserção de faixas de pedestres, iluminação apropriada, arborização e medidas pontuais em praças - como inserções de bancos, poda das árvores e limpeza.

Com a garantia de espaços livres públicos qualificados, as escolas ganham mais ferramentas para explorar as possibilidades educativas do território. $\mathrm{O}$ aprendizado do lado de fora da edificação traz novas dinâmicas ao dia-a-dia escolar, colocando em pauta a complexidade do contexto - territorial e comunitário - onde a escola está inserida. As crianças e jovens podem experimentar uma forma de aprendizagem ativa, movida pela curiosidade e baseada nas experiências sensoriais.

Uma forma de iniciar a articulação com o território é propor passeios pelo bairro com os estudantes, objetivando a identificação de espaços que permitam a articulação de redes ou que podem ser utilizados para atividades que geralmente acontecem apenas na sala de aula. É preciso identificar os desafios e as potencialidades dos espaços disponíveis e atentar à infraestrutura existente no local, observando o sombreamento, a presença de abrigo para chuva, a disponibilidade de sanitários e espaços de descanso.

A aprendizagem na cidade deve ser reconhecida e incorporada como aspecto do currículo, sendo uma importante dimensão da educação integral. Harvey destaca: "A questão do tipo de cidade que desejamos é inseparável da questão do tipo de pessoa que desejamos nos tornar" (HARVEY, 2013, p. 28). Dessa forma, o espaço da cidade diz respeito também à nossa concepção como indivíduos. "A modificação social requer a modificação do espaço de convivência. A modificação na forma de tratamento do espaço requer uma intenção de modificação dos modos de convivência" (BARBUY, 1980, p. 41). A busca por um modo de vida saudável passa necessariamente pelo tratamento dos espaços - da escola e da cidade - e pelas possíveis interações com os mesmos. Uma vez compreendido o papel do território na formação integral do indivíduo, fica evidente a relevância de enfatizar o vínculo entre escola, território e comunidade na constituição de uma metodologia para escolas saudáveis.

\section{Desdobramentos}

No desenvolvimento desta escrita, foram percorridas concepções conceituais e articulações a partir do conteúdo trazido pelo Manual Técnico para Escolas Saudáveis como forma de analisar, não o produto concretizado, mas os processos que já são desdobramentos de sua elaboração. Como pensar o ambiente escolar a partir de pressupostos saudáveis?

Retoma-se, assim, as premissas e os temas subjacentes à gestão democrática a fim de contribuir com uma conjuntura do debate escolar que expressa conflitos e desigualdades. Como possibilidade de construção colaborativa e, sobretudo, contra-hegemônica, acredita-se em escolas que ofereçam um ambiente proveitoso aos desejos e singularidades derivadas do território. Desta maneira, como resultado, atenta-se às questões metodológicas que estão contidas nesta discussão. 
Os caminhos para a constituição de escolas efetivamente saudáveis se estruturam a partir da tríade: território educativo, currículo e gestão democrática. Esses aspectos são eixos transversais de uma metodologia que se inicia a partir de um diagnóstico participativo da escola, seguido por um plano de ação (de curto, médio e longo prazo) estruturado coletivamente.

Dado o contexto da pandemia de COVID-19 e as aulas não presenciais, propõe-se que um primeiro diagnóstico possa ser realizado antes mesmo do retorno físico ao ambiente escolar. Uma etapa preliminar consistiria no compartilhamento, seguido de debate com toda comunidade escolar, sobre documentos como o Plano Político Pedagógico da escola e o currículo atribuído a cada ano. Entendidos coletivamente os princípios que regem a escola - em seu âmbito pedagógico e político - o primeiro passo para a construção de uma escola saudável é a inserção de um processo de escuta bem estruturado. Para tanto, propõe-se a criação de diferentes grupos intra-segmentais (alunas e alunos, funcionárias e funcionários, professoras e professores, gestores e gestoras, famílias e comunidade), intergeracionais e que contemplem a diversidade de gêneros, sexualidades, raças, etnias, etc. Os indivíduos, em suas pluralidades, habitam o mundo de diferentes formas e, portanto, têm percepções de mundo também plurais. Estas percepções criam, por sua vez, diferentes entendimentos, que devem ser contemplados em um processo colaborativo para a constituição de um novo espaço escolar saudável e possível para todos: "Se nós pensarmos que o território se constitui não de cima para baixo, mas de baixo para cima, vamos ver que a questão de sentir o espaço é tão ou mais importante do que a questão de entendê-lo" (SODRÉ, 2020, p. 113).

As percepções dos indivíduos sobre o espaço podem adquirir dimensões coletivas ao serem debatidas em um contexto de gestão de base democrática, onde as diversas vozes são ouvidas e consideradas na delimitação e deliberação de ações. Dessa forma, as singularidades, como apresentadas por Foucault (1995), podem adquirir importância para a prática coletiva.

Os grupos plurais devem, a princípio, buscar olhar os diferentes espaços da escola, identificando novas possibilidades de uso e pensando maneiras de torná-los mais saudáveis. É importante considerar todos os espaços da escola em seus diferentes usos e turnos (manhã, tarde e noite) e em todos os dias da semana (inclusive aos finais de semana). Os grupos podem, para a sistematização das informações, receber fichas com uma enumeração dos espaços, a serem preenchidas a partir das percepções individuais.

Além dos intra-escolares, os espaços para além dos muros devem também ser considerados, compreendendo que a escola e o território onde se insere fazem parte de um todo interconectado que configura um território educativo. A compreensão do território como potência pedagógica deve englobar um momento de construção de consciência territorial a partir de atividades e vivências no próprio território.

Leonardo Boff (1997), na parábola A águia e a galinha, aponta que pensamos a partir do chão que pisamos. Dessa forma, o território possibilita pensar sobre nós e nosso modo de habitar o mundo.

A sugestão é que, em uma metodologia para a construção de uma escola saudável, cada escola olhe para o "chão que pisa", sobre como se dá a forma e a organização escolar, identificando as relações entre os componentes que compõem o território: os objetos e as ações, segundo nos ensina o geógrafo Milton Santos. É um exercício de perceber com mais atenção cada canto da escola e de seu território, seus espaços construídos e não construídos, e compartilhar estas percepções. Ao mesmo tempo, é preciso observar as ações, as rotinas e como esses campos - dos objetos e das ações - se influenciam mutuamente. (INSTITUTO DOS ARQUITETOS DO BRASIL, 2020, p. 44).

A partir das percepções espaciais, e tendo em mente a questão de "como construir espaços saudáveis?", surgem algumas perguntas anteriores: $\mathrm{O}$ que tem neste espaço? O que ele me diz? O 
que sinto neste lugar? O que esse lugar me faz pensar? O que nesse lugar pode ser alterado para me fazer sentir melhor física e psicologicamente?

Metodologicamente, e buscando constituir parâmetros de gestão democrática, sugere-se que, a partir das discussões em grupo, sejam delimitadas sugestões de respostas a estas perguntas e que sejam deliberados representantes para compor um encontro geral de compartilhamento das discussões. Cada segmento - estudantes, funcionários, professores, familiares, membros da comunidade - pode assim apresentar aos demais seus pontos de vista e questionamentos levantados, sendo estes sistematizados e escalonados em muito, médio e pouco importantes para os objetivos de uma escola saudável. Essa organização estabelece o núcleo de uma gestão democrática, com vistas a tornar-se cada vez mais complexa e perene na dinâmica escolar.

Desses questionamentos e sugestões, discutidas e compartilhadas com todos, é importante definir prioridades e estratégias de ação, constituindo um plano comum a ser colocado em ação com prazos e responsáveis.

\section{Considerações finais}

O cenário ao qual a educação e os ambientes escolares estiveram submetidos em 2020 acirra desigualdades, abrindo um campo de reflexão, elaboração e constante atualização crítica de novas narrativas que incorporem a perspectiva e a experiência prévia de todos os membros da comunidade escolar. É junto, coletivamente, que se propõe aprofundar esta reflexão, de modo a criar bases para intervenções no âmbito de tornar os espaços escolares e urbanos saudáveis.

Nesse sentido, o cenário apresenta pistas de circunstâncias e intensidades fundamentais para repensar a escola, sua construção e sua dimensão saudável. Dimensão esta que, a partir da articulação conceitual com o campo da educação e suas abrangências, considera não só as qualidades do ambiente construído, mas a interlocução integral do espaço e as expressões singulares que o compõem. Para além de apontamentos técnicos e protocolos sanitários, é urgente que a escola e seu cotidiano sejam praticados a partir de diálogos com a educação integral, a gestão democrática e as práticas pedagógicas de um território educativo. Pois é na dimensão ético-estética da prática pedagógica que estão os pilares de uma nova escola, onde o corpo, o espaço escolar e o espaço da cidade conectam-se a fim de produzir, efetivamente, um ambiente saudável.

Não se trata de voltar ao normal, mas reinventar a escola (SINGER, 2020). E, na direção a um ambiente verdadeiramente saudável, que essa reinvenção seja feita não mais a portas fechadas, mas sim com a participação de toda comunidade escolar e através de processos interdisciplinares, nos quais arquitetos, educadores e artistas têm muito a contribuir.

\section{Referências}

APPLE, Michael; BEANE, James (org.). Escolas Democráticas. São Paulo: Cortez, 2001.

ARRUDA, Felipe (org.) Prêmio Territórios: ideias sobre educação integral e a relação escola-território. São Paulo: Instituto Tomie Ohtake, 2020.

BARBUY, Santiago. O espaço do encontro humano. São Paulo: ECE, 1980.

BOFF, Leonardo. A águia e a galinha, a metáfora da condição humana. 40. ed. Petrópolis: Vozes, 1997.

BRASIL. Série Mais Educação: Territórios Educativos para Educação Integral. Brasília, DF: MEC, 2009. Disponível em: http://educacaointegral.org.br/wp-content/uploads/2014/04/ territorioseducativos.pdf. Acesso em: 28 out. 2020. 
CANÁRIO, Rui. A escola tem futuro? Das promessas às incertezas. Porto Alegre: Artmed, 2006.

CURY, Carlos Roberto Jamil. A gestão democrática na escola e o direito à educação. Revista Brasileira de Política e Administração da Educação, Porto Alegre, v. 23, n. 3, p. 483-495, 2007.

FOUCAULT, Michel. O sujeito e o poder. In: DREYFUS, Hubert Lederer; RABINOW, Paul (org.). Michel Foucault, uma trajetória filosófica: para além do estruturalismo e da hermenêutica. Rio de Janeiro: Forense/Universitária, 1995. p. 231-249.

FREIRE, Paulo. Política e educação. 5. ed. São Paulo: Cortez Editora, 2001.

GOMEZ-GRANELL, Carmen; VILA, Ignacio (org.). A cidade como projeto educativo. Porto Alegre: Artmed, 2003.

INSTITUTO DOS ARQUITETOS DO BRASIL. Grupo de Trabalho Cidade, Infâncias e Juventudes. Manual Técnico Para Escolas Saudáveis. São Paulo: IAB, 2020. Disponível em: https://www.iabsp.org.br/manual-tecnico-para-escolas-saudaveis/. Acesso em: 04 maio 2021.

HARVEY, David. Cidades rebeldes: passe livre e as manifestações que tomaram as ruas do Brasil. Textos encomendados. São Paulo: Editora Boitempo, 2013.

INSTITUTO ALANA. Planejando a reabertura das escolas: a contribuição das pesquisas sobre os benefícios da natureza na educação escolar. São Paulo: Programa Criança e Natureza, 2020. Disponível em: https://criancaenatureza.org.br/ wp-content/uploads/2020/08/Planejando-a-reabertura-das-escolas.pdf?utm_source=whatsapp\&utm_medium=social\&utm_campaign=reabertura-das-escolas. Acesso em: 10 jan. 2021.

INSTITUTO RODRIGO MENDES. Protocolos sobre educação inclusiva durante a pandemia da Covid-19: um sobrevoo por 23 países e organismos internacionais. [S. l.], 2020. Disponível em: https://fundacaogrupovw.org.br/wp-content/ uploads/2020/07/protocolos-educacao-inclusiva-durante-pandemia.pdf. Acesso em: 29 jan. 2021.

IUNES, Nailê Pinto; LEITE, Maria Cecilia Lorea. A gestão democrática recontextualizada na escola em experiências de democracia participativa. In: REUNIÃO ANUAL DA ANPED, 33., 2010, Caxambu. Anais [...]. Caxambu, 2010, v. 1. p. 1-17.

KRENAK, Ailton. Ideias para Adiar o Fim do Mundo. São Paulo: Companhia das Letras, 2019.

SANTOS, Boaventura de Sousa. A cruel pedagogia do vírus. Coimbra: Edições Almedina, 2020.

SANTOS, Milton. Por uma outra globalização: do pensamento único à consciência universal. Rio de Janeiro: Record, 2000.

SINGER, Helena. Não voltar, recriar a Escola. In: CENTRO de referências em educação integral. [S. l.], 18 set. 2020. Disponível em: https://educacaointegral.org.br/reportagens/nao-voltar-recriar-escola/. Acesso em: 05 out. 2020.

SODRÉ, Muniz. Reinventar a educação é habitar o território do sensível. [Entrevista concedida a] Divina Prado. In: ARRUDA, Felipe (org.). Prêmio territórios: Ideias sobre educação integral e a relação escola-território. São Paulo: Instituto Tomie Ohtake, 2020. p. 111-123.

THE AMERICAN INSTITUTE OF ARCHITECTS. Reopening America: Strategies for Safer Schools. [S. l.]: The American Institute of Architects, 2020. Disponível em: https://content.aia.org/sites/default/files/2020-08/Reopening_America__Strategies_for_Safer_Schools_June_2020_.pdf. Acesso em: 26 abr. 2021.

UNESCO. Marco de ação e recomendações para a reabertura de escolas. [S. l.]: Unesco, 2020. Disponível em: https:// unesdoc.unesco.org/. Acesso em: 29 jan. 2021.

Data de submissão: 30/01/2021

Data de aceite: 16/06/2021 